\title{
BIM 技术在建筑施工中的应用
}

\author{
李建英 罗瑜
}

中国建筑土木建设有限公司，北京 100000

[摘要] 随着科技的进步, 社会发展的各行各业都开始朝着信息化、智能化发展, 尤其是互联网和信息技术普及应用, 给社会发展 和市场活动带来了全新的模式。建筑工程作为经济发展的重要组成部分, 不仅对经济发展影响巨大, 同时也与城市建设密切相 关。由于当前对于建筑工程规模更大、内容更多、功能更全, 导致其施工难度也随之提升。为了更好地实现建筑工程高质量施 工和全方位管理, B I M 技术逐渐被应用并且普及开来。下面, 文章就 B I M 技术在建筑施工中的应用展开论述。

[关键词]建筑施工; BIM 技术; 技术应用

DOI: $10.33142 /$ ec.v4i3.3496

中图分类号: TL372+.2

文献标识码：A

\section{Application of BIM Technology in Construction}

\author{
LI Jianying, LUO Yu
}

China Construction Civil Engineering Co., Ltd., Beijing, 100000, China

\begin{abstract}
With the progress of science and technology, all walks of life of social development have begun to develop towards informatization and intelligence, especially the popularization and application of Internet and information technology, which has brought a new model to social development and market activities. As an important part of economic development, construction engineering not only has a great impact on economic development, but also is closely related to urban construction. Due to the larger scale, more content and more complete functions of the current construction project, the construction difficulty is also increased. In order to better achieve high quality construction and all-round management of construction engineering, BIM Technology is gradually applied and popularized. Next, the article discusses the application of BIM Technology in construction.
\end{abstract}

Keywords: building construction; BIM Technology; technology application

\section{引言}

现代社会，我国的经济和科技都得到飞速的发展，建筑业方面也取得了不小的成就。在建筑施工过程中科技手段 的应用越来越全面, 特别是 BIM 技术的应用, 促进了建筑行业更快的发展, 在很大程度上提高了我国建筑行业的经济 效益。怎样在建筑施工中正确合理的应用 BIM 技术，需要专业的设计师和技术人员进行系统、全面的思考。

\section{BIM 技术简述}

BIM 技术也就是建筑信息模型, 这一技术通过三维建模实现图纸立体化、可视化。通过建立 BIM 三维模型, 能够对建 筑工程中的所有构建信息、相关参数准确反映, 与此同时还可以对施工过程动态演示, 能够将工程信息和参数直观传递 给管理人员, 将现场管理效率大大提升。对于建筑工程项目来讲，具有图纸复杂、信息繁琐、施工管理管理难度大等特 点, 借助 BIM 技术可以将工程项目所有数据转化为直观数据形式, 通过建立信息系统实现数据查阅实时、快速, 现场管 理人员能够在管理工作中有效结合动态三维模型, 利用模型实现工程质量、工程安全有效保证。通过利用 BIM 技术, 能 够实现项目施工安全、施工质量、施工进度、施工成本管理同步进行, 因此在建筑工程施工项目中有着非常广泛地应用, 特别是大型建筑工程能够实现流程简化。当前建筑工程项目中 BIM 技术已经成为重要趋势, 因此建筑施工企业必须要认 识到这项技术的重要性, 利用这一技术确保建筑工程项目安全、高效、高质量完成, 实现我国建筑行业快速进步和发展。

\section{BIM 技术的施工过程中的应用要点}

2. 1 BIM 在建筑施工前期的应用

BIM 技术在建筑施工中有程序化的特点, 设计师在进行建筑施工项目投资和设计前期, 通过 BIM 技术的指导, 对施 工的数据进行系统的分析, 从而使建筑项目工程的划分更加具体清晰, 并且有效避免建筑过程中投资和安全的风险。

\section{2 BIM 对建筑施工场地布置中的应用}

在建筑行业, 有很多项目的规模较大, 因此就需要对施工现场进行合理布局, 才能保证施工的顺利进行。运用 BIM 技术对施工场地的面积和运输材料的车辆所需空间进行计算, 并进行科学、合理的布置, 避免由于场地布置不合理, 造成材料无法运送到指定地点或者影响正常车辆通行的情况。

\section{3 BIM 技术在建筑施工过程数据系统中的应用}

BIM 技术是以数据信息处理为依据的一种技术手段, 目前在建筑施工中数据系统中应用广泛。BIM 技术主要是对相 
关数据进行处理、分析和储存等。另一方面, BIM 技术人员以建筑的特点为依据, 对数据进行录入, 对各项数据进行转 化，通过对数据的运算加工、分析、处理、分类保存等，使建筑施工在实际操作中更具程序化。

\section{4 BIM 技术在建筑施工过程中所需费用管理上的应用}

在建筑施工过程中，造价管理都是非常重要的一部分。良好的造价管理系统可以有效节约施工成本，使施工过程 能够有序进行, 同时促进企业的发展, 提高企业经济收益。BIM 技术在费用管理方面的应用, 主要体现在以下几方面: 对施工投资的预算、施工过程中对资金的管理以及竣工后资金的结算。经过系统的数据分析，建筑投资方能够更客观 的体会到项目存在的潜在利益, 以及发掘项目中的潜在风险, 从而减少投资方对项目进行错误的判断, 另一方面, 在 项目的施工过程中, 根据相关的数据进行分析, 将项目成本控制在合理范围内, 能够合理掌握资金的流动方向以及对 成本的管理，避免造成在施工过程中出现资金去向不明以及成本失控的现象。在竣工的资金结算中，根据 BIM 技术对 数据的详细分析和整理，能够有效避免建筑投资方对资金去向的想象，减少在建筑施工中资金等风险的发生。

\subsection{BIM 技术在施工管理中的应用}

建筑施工管理也是建筑施工过程中的重要组成部分，同时对 BIM 技术的应用也比较广泛。BIM 技术不仅在建筑工程 中对资金管理的意义重大，对保障施工人员的安全以及施工质量也至关重要。在建筑施工过程中，技术人员可以运用 BIM 技术对三维立体模型中显示的风险因素进行排查可, 并在实际的施工过程中, 做好预防计划, 从而有效避免危险的 发生; 在对施工质量的把控方面, 技术人员可以通过 BIM 技术手段对实际施工过程中的数据进行分析和处理, 并及时 发现和解决施工项目中存在的安全隐患; 在对项目施工管理方面, 技术人员可以根据 BIM 技术对数据和信息进行快速 的分析和整理，并对项目的实施过程进行监督，从而有效提高施工人员的工作效率，并加快工程的进度。

\section{BIM 技术在建筑项目施工中的实际应用}

\section{1 构建项目结构三维模型}

通过构建 BIM 信息模型, 能够试下建筑工程项目科学模拟, 借助 BIM 技术软件开展三维模型构建, 直观展示出建 筑工程项目整体概况。在进行三维模型构建具体过程中, 作为现场管理人员需要将工程施工进度计划准确导入, 按照 工程项目具体施工任务进行集合，利用模拟动画工具实现建筑工程项目全过程三维模拟。

对于建筑工程项目来讲, 通常施工规模都是比较大的, 再就是建筑工程施工流程都比较复杂, 因此要求施工人员 具备丰富的施工经验, 通过分解建筑工程项目为多个基础单元, 利用软件进行施工进度合理编制, 将施工工期与工作 任务之间的关系充分明确。

对于建筑工程项目, 为了能够将建筑工程建设内容充分表达, 就需要用到大量图纸。对于某些建筑工程项目, 由于 施工流程相对比较复杂会导致施工图识别难度大大增加。还有就是, 建筑工程项目内部具有较多单位结构, 每个单体结 构都比较复杂且种类繁多, 如果继续沿用常规二维图纸就使得施工人员不能对工程设计意图全面了解, 容易导致施工出 现问题。为了能够有效改善此类问题, 就需要使用 BIM 技术进行三维模型构建, 这样能够保证工程项目内部之间信息传 递, 有效避免不应该出现的错误。对于建筑工程结构三维模型, 现场管理人员能够实现全方位、无死角分析, 能够让施 工人员快速找到建筑结构内部孔洞、预埋件等的位置, 方便快速进行工程施工, 为后续建筑物得检查核复核提供便利。

\section{2 BIM 组织架构}

通过利用 BIM 技术能够将建筑工程设计方案有效调整，对工程施工管理模式进行优化，实现工程组织架构合理调整，现在 提升工程建设项目管理水平。由于建筑工程项目具有复杂的结构, 项目工程量也比较大且设备材料与种类比较多。这些因素的存 在, 使得建筑工程组织架构非常复杂, 因此需要借助 BIM 技术进行参数化模型构建, 充分借助 BIM 技术所具有的可视化特点, 将 组织架构中存在的薄弱环节找出, 提前对其进行优化作出改进, 在不对工程管理效率造成影响到前提下尽可能减少设备材料耗损。

还有就是, BIM 技术是建筑工程智慧工地建设重要组成, 只有保证 BIM 技术全面应用, 才能够实现智慧工地建设目 标。在项目正式进行施工工作之前, 要求对项目进行针对性模拟, 通过模拟可以让管理人员对各个施工环节之间联系 能直观了解, 对工程施工中存在的问题借助软件实现有效分析, 对原因仔细分析后找出有效的解决方法。与此同时, 对于建筑工程项目具体施工过程中, 通过使用三维施工模型能够帮助施工人员对图纸信息深层次了解, 将因为解读信 息导致的错误有效减少。作为建筑工程项目现场管理人员, 通过应用 BIM 技术可以实现组织架构微调, 能够全方位、 全过程管理项目，将工程项目经济效益全面提升的同时，有效减少管理不规范得情况。

\section{4 结束语}

总而言之，对于建筑工程项目要充分认识到 BIM 技术优势，通过合理应用 BIM 技术提高建筑施工整体质量。在进 行 BIM 技术应用过程中, 需要对 BIM 技术操作原理充分了解, 在掌握具体原理以后根据项目特点进行建模, 在保证建 筑工程项目安全性的基础上应用 BIM 技术。对于 BIM 技术的具体应用, 实现建筑工程质量充分保证的同时, 将项目施 工周期进一步加快, 实现工程项目成本有效降低, 最终保证建筑工程项目经济效益最大化。希望通过上文论述, 能够 促进 BIM 技术更好的应用到建筑工程施工中去。

\section{[参考文献]}

[1] 郭慧锋,曾日亮. BIM 技术在建筑施工中的应用研究 [J]. 价值工程, 2019,38(10): 154-158.

[2] 冯超. BIM 技术在建筑工程施工中的应用 [J].中小企业管理与科技 (上旬刊) , 2016 (11) : 45-46.

[3]王春涛,陈留兵. BIM 技术在建筑工程施工中的应用 [J]. 南通职业大学学报, 2015,29(2): 81-85.

作者简介: 罗瑜（1987-）女，东北大学，本科，土木工程，中国建筑土木建设有限公司，安全专业工程师。 